\title{
FORMAL RULES, INFORMAL RULES, AND ECONOMIC PERFORMANCE
}

\author{
AN ORGANIZING FRAMEWORK
}

\author{
J. WINIECKI
}

(Received: 14 December 2000; revision received: 14 March 2001;

accepted: 3 April 2001)

\begin{abstract}
In this article the author tries consider a question important for economic development: what happens when formal rules and informal rules of economic behaviour are in conflict. Under such circumstances even the best, wealth creation-enhancing rules must bring about different outcomes if introduced in the different political, economic, and socio-cultural environments.

These considerations begin with the overview of possible balances and imbalances in the relationships between formal and informal rules and potential conflicts that may arise in the latter cases. The next step is the selection of institutional characteristics that facilitate the explanation and prediction of outcomes of formal rules-informal rules' interactions. The third, and final, step considered in the article concerns the adjustment of rules (formal, informal, or both) over time and possible patterns of adjustment.
\end{abstract}

Keywords: institutions, institutional characteristics, economic development, economic incentives, property rights, rules (regulations), formal and informal, rulers (ruling strata)

JEL classification index: K2, K22, O3

\section{PRELIMINARIES}

There are, by now, established strands in economic theorizing, stressing the importance of institutions, formal and informal, in economic development. The research on institutions, and their impact on wealth creation (understood here as synonymous with economic development) becomes more and more varied over time as new strands of neo-institutional theorizing emerge on the one hand and reformulations and extensions of the fundamentals are taking place on the other.

This essay is more in the nature of the latter search. The present writer looks at the relationship between institutions and economic performance trying to find, as

Correspondence: J. Winiecki, Chair of International Trade and Finance, European University Viadrina, Grosse Scharrstr. 59, 15230 Frankfurt (Oder), Germany. E-mail: winiecki@polbox.pl 
a first step, an answer to an important question: "What happens, in terms of wealth creating potential, when formal rules and informal rules come into conflict with each other?" How such conflict, reflected in people's behaviour deviating from one predicted on the basis of introduced formal rules affects both transaction costs and neoclassical production costs in the economy, via changes in the structure of incentives? Thus, what is its effect on economic performance?

An answer should, hopefully, reveal internally coherent and systematic regularities through the process of reviewing a variety of historical and contemporary cases of economic development, economic stagnation, or retrogression. Before, however, I delve more deeply into the basic relationships concerning the issue in question, the most important terms used so far should be spelled out in order to reduce the terminological confusion.

Thus, institutions are defined as spontaneously arisen, as well as humanly devised arrangements shaping repeated human interactions (Voigt, 1993), modifying North (1990), to allow for spontaneous emergence of norms. Formal institutions, or formal rules, are constitutions, codes, statutes, and other legislative acts, as well as common law and administrative regulations. Much more varied informal institutions, or informal rules, consist of customs and other tradition-based conventions, religious and ideological beliefs, self-imposed codes-of-conduct, etc.

Next, property rights are relations among individuals, arising from the existence of scarce goods and pertaining to their use. Lastly, transaction costs are encompassing those related to the creation, restructuring and enforcement of institutions, as well as costs of using these institutions by market participants (Pejovich, 1990; Furubotn and Richter, 1991). Neoclassical production costs are standard economic textbook production costs (Williamson, 1992).

In contrast to many neo-institutional economists, the present writer does not neglect the potential contribution of changes in neoclassical production costs (NPCs for short), for it may happen that the newly introduced formal rules, although temporarily raising the transaction costs (TCs for short), they at the same time reduce NPCs. So, the aggregate production costs (NPCs + TCs) may, in fact, decline and wealth creation capabilities are enhanced. Recent experience of post-communist transition in East-Central Europe is an excellent, if often underappreciated, example.

The research agenda of this essay consists of three steps. In the first step, I consider interaction between formal rules (FRs for short) and informal rules (IFRs). I begin my considerations with the assumption of a balance between the two sets of rules that exists in a society. This balance may be upset in two ways. On the one hand, changes in formal rules establish new incentives to economic development, or disincentives, as it has often been the case in economic history. These affect the 
behaviour of economic agents who respond to the resultant changes in TCs and NPCs in the economy. The ability of new FRs to free resources for alternative, higher efficiency uses or, alternatively, tie them (often for long) in low efficiency uses, affect the wealth creating capability of the economy. But the extent to which FRs are able to affect that wealth creating capability is not determined by FRs alone. In real life, in contrast to the ideal world of the neoclassical economic theory, there is a lot of friction, created by the FRs-IFRs interaction. On the other hand, the existing balance may be upset by the incremental evolution of informal rules that may increasingly undermine certain conventions, codes-of-conduct, and beliefs that earlier were the cornerstone of, or at least important for, a given social and economic order and supersede them with modified or, in the limit, radically altered IFRs. Such developments necessarily influence the political process through which the modified, or radically altered, FRs - that aim at creating new concordance with IFRs - are introduced into the economy.

In the case of the first route - from FRs to IFRs - the stylized pattern is expected to run as follows. New FRs create new or restructure old institutions. By virtue of that very fact transaction costs are incurred, due to, at a minimum, the necessity of learning new rules, applying them in a consistent manner, imitating those who apparently apply these rules consistently (and evidently advantageously to themselves), engaging in conflict resolution procedures, etc. This process is temporarily reducing benefits from the introduction of new FRs as transaction cost-reducing and neoclassical production cost-reducing devices. (The opposite, that is temporary limitation of negative effects of disincentives introduced by the new FRs, is also true - see below.)

More importantly from the vantage point of the theme of this essay, FRs come, more often than not, into conflict with the existing informal rules. For this to happen, the new FRs need not be drastically different from the old ones. However, IFRs are, to some extent, long term adjustments to the preceding formal rules, and the change, even if its thrust is, by and large, in the same direction, may generate friction as another adaptation process has to take place. When new FRs are indeed radically different, the amount of friction correspondingly increases, sharply reducing the expected economic development effects of new FRs, in the short to medium run at least. In the extreme cases IFRs may make these effects almost unrealizable.

In the case of the second route, FRs following modified or altered IFRs do not create any particular analytical problems. Friction is very limited there. Conflicts ensue only when FRs try to reaffirm a given old order whose economic underpinnings have been eroded, due to, i.e., the emerging new IFRs.

The institution of serfdom, for example, came into such conflict in Western Europe with the growing pressure of the peasantry to free themselves from the shack- 
les of non-pecuniary relationships with their feudal lords. The story is well presented in Miskimin (1969). Peasants' efforts were supported by both long term economic processes and discontinuous events. The progressing commercialization of the Western economy increased incentives not only for peasants but also for their lords to shift the relationships to pecuniary ones. Also, the balance of supply and demand for peasant labour shifted in favour of suppliers, as growing cities gave the peasantry a much desired alternative. The discontinuous event, the 'Black Death' of the 14th century, changed the balance even more drastically. However, given the political preponderance of landlords over tenants, the FRs of 14th-15th-centuries' Europe are replete with statutes, ordinances, and other formal rules that limited money wages, decreed the first claim of the local lord on labour services of those peasants living on a given territory, forbade labour mobility without a written consent of the local lord, etc. Such rearguard action was, however, to no avail and the economic reality slowly triumphed in the form of changed, monetized landlord-tenant relationships. Formal rules were, subsequently, changed or often simply left unenforced and, over time, unenforceable.

The second step of the research agenda is to search for certain institutional characteristics that may help us to explain and predict the outcomes of new FRs old IFRs interaction in terms of the capability of the former to create new wealth or redistribute old one. For it seems intuitively plausible that some institutional characteristics of a given polity, society, and economy may facilitate the adaptation (whether of informal rules to formal rules, or the vice versa), while others may not or may actually make it more difficult, that is, more costly in terms of TCs and NPCs. A list of such characteristics, as well as theoretical underpinnings that would give such list the desired internal consistency, become then, the next task.

A list of institutional characteristics helping the analyst to turn cases into patterns should bring us closer to the discovery as to whether it is possible to test (non-econometrically) a variety of real-life cases of FRs' changes and obtain meaningful, coherent and systematized answers. The selection of these characteristics seems to be very important in this respect.

Finally, the present writer turns to the third element of the research agenda that should be considered in this essay, namely the role of time. It has been so far only implicit in these preliminaries, when this author stressed that friction between FRs and IFRs stems at a minimum from the fact that IFRs are often in part societal adjustments to earlier FRs. For this implies that IFRs do adjust, slowly and sometimes discontinuously (as it will be shown later in this essay), to changes in formal rules.

The process of such adjustment, changing the cost/benefit calculation of the introduction of new FRs over time, seems to be of importance for the wealth creation, wealth reduction, and wealth redistribution outcomes of FRs-IFRs interac- 
tion (see Pejovich, 1998). In such a process certain FRs are abandoned, while some others are reinforced by a stream of secondary FRs aimed at either restoring the original purpose of earlier introduced FRs or, conversely, facilitating the FRs' adaptation to the resilient (and earlier underestimated) informal rules.

The role of time is no less important in analyzing the incremental (or sometimes even discontinuous) changes in IFRs that at a certain point are translated into new FRs through political process.

\section{THE FRAMEWORK FOR FRs-IFRs INTERACTION}

To begin with, one should start with the balance conditions between the formal rules and informal rules in the economy. These conditions exist, whenever there is a harmony between the current FRs and IFRs, so that little further behavioural adaptations on the side of economic agents are necessary. The foregoing does not mean that no IFRs' adaptations are made at the margin. Nor does it exclude some adaptations of FRs through secondary rules. The balance - and balance is a more suitable term than the much overused equilibrium - means that neither decision makers (rulers in non-representative, or 'predatory', states), nor economic agents perceive that their interests require fundamental institutional change.

Of course, it is the decision makers (rulers) who have the power to change the FRs and any proposal for change coming from others is evaluated by them from the viewpoint of their interests (save the case of Northian 'social reformers', later defined as strongly ideologically motivated decision makers (cf. North, 1979 and 1981). The balance means that the rulers do not feel the need to change the structure of incentives via new FRs, in order to increase their share of the created wealth or increase the volume of created wealth with the unchanged share. At the same time it means that no organized groups of economic agents is able to successfully press for changes in FRs to improve the structure of incentives that would increase efficiency, i.e. wealth creating capability of the economy that would allow them to increase their wealth.

It should be noted that what has been described here as a balance does not in itself imply any assessment of the level of performance of such an economy. A balance can be achieved by any economy, at any level of economic development. You may find such a balance in a Misesian 'evenly rotating' capitalist market economy within the framework of a liberal state (such as, for example, West European or U.S. economies of the late 19th century) or in an ancient agrarian economy with the total power, including property rights to the produced wealth, concentrated in the hands of a ruler-God (such as, e.g., Egypt under the pharaohs), or for that matter in the stateless pastoralist societies (i.e. in pre-colonial Africa). 
Some adjustments in either FRs or IFRs, or both, may be made at the margin, but there is no doubt that both sets of rules displayed for decades or even centuries remarkable stability.

More topical for the theme of this essay are, however, conditions of imbalance. The opening paragraph of this section suggested aims of such a change. Thus, the change may be initiated by a ruler (ruling group, decision makers in a representative, parliamentary democracy) who for one reason or another desires to alter the structure property rights to increase his (their) 'take'. And it does not matter whether the ruler does this in response to increased desire for conspicuous consumption, new requirements of warfare (as European kings did in the age of early absolutism), or a representative government does it to maintain itself in power in the face of costly electoral promises that have to be at least partly fulfilled before the next elections. In either case the source of imbalance is the redistributive initiative. Increases in conspicuous consumption of kings, satraps, and other rulers in Northian 'predatory states' fit into this category as well. In fact, many so-called 'Third World' regimes fit well into the predatory state pattern.

An alternative rationale for change has historically been demands of various organized pressure groups in the society for change in the structure of incentives affecting wealth creation. These groups perceive that, given the changes in technology, organizational capabilities, factor supplies, tastes, etc., they could benefit from economic development, or to put it differently, from increases in wealth, created as a result of the changes in FRs that improve the structure of incentives and result in the reallocation of resources to more value adding uses. In both cases of ruler-initiated and pressure groups-initiated rearrangements of property rights assessments were usually made about the possible costs to the initiator(s) of such a move (coalition-building costs, buying-off costs, etc.).

One type of pressure, not mentioned so far, concerns the cases, where more or less well organized groups other than the ruling stratum, pressure for redistribution of the existing wealth to themselves. If they are successful, the 'take' of the privileged groups in the produced wealth will increase; in other words, they will be willy-nilly coopted by the ruling stratum. These cases are not analytically interesting as they are identical in their impact on economic performance to the cases of ruler-initiated redistributive initiatives. In both types, disincentives to increase wealth will rise.

One way or another, this author agrees with Eric Jones that "economic history may be thought of as a struggle between the propensity for growth and one for rent-seeking [or more widely redistribution - J. W.], that is, for someone improving his or her position, or a group bettering its position, at the expense of the general welfare" (Jones, 1988, p. 1). However, Jones' definition must be extended to those cases, where trade-offs between the two tendencies are possible. New or, 
more often, modified formal rules enhance incentives to create wealth but these developments rearrange rather than eliminate redistributive activities. The outcomes should be seen in more/less (more economic development/less rent seeking) rather than either/or categories; in a movement along the continuum rather than binary choices.

Whether for wealth creation or wealth redistribution purposes, changes in FRs historically interacted with IFRs and the effects of this interaction is what interests the present writer most. What should be stressed at this point is that such changes are never independent of the prevailing social and economic conditions of life.

What happens is that usually technical changes, changes in economic organization, social changes - all create new opportunities for economic development but those interested in implementing changes find them blocked by the existing structure of property rights. As it has often happened in economic history, the overwhelming power of the forces in favour of the status quo may stem the growing pressures for change and nothing is done to modify the property rights. Historical cases of Imperial China's thwarting, at important crossroads, necessary changes that would facilitate economic development belong to that category. The Soviet communist economic system that collapsed rather than modified its structure of incentives is another, contemporarily more obvious, example.

However, if the resistance to change has not been overwhelming, a range of pressures (demonstration effect of success elsewhere, changing economic position of some organized groups or strata, successful forging of coalitions in favour of change, etc.) may result in the introduction of economic development, that is, wealth creating enhancing measures.

Such changes unavoidably bring about the interaction between the new FRs and prevailing IFRs. Now, it is only logical to expect two alternative outcomes of that interaction. On the one hand, if new FRs are (largely) in harmony with the prevailing IFRs, then harmonious interaction rapidly reduces transaction costs and/or neoclassical production costs by releasing resources from their present uses to those with greater potential for increases in wealth. On the other, when FRs conflict with IFRs, the resultant friction ties resources largely where they have already been employed and limits, often sharply, gains from expected reduction in transaction costs. Thus, discordance between FRs and IFRs creates - at least initially - an economy characterized by higher transaction costs than otherwise would have been the case.

True, in accordance with an opinion presented earlier, the increase in transaction costs may be more than compensated by concurrent decrease in neoclassical production costs. Introduction of radical economic stabilization cum liberalization measures, coupled with the dismantling of the political/economic institutional structure of communism and freeing the entrepreneurial spirit of the people right 
at the start of post-communist transition in East-Central Europe, much reduced NPCs. This reduction more than compensated for the increase in TCs resulting from the slow build-up of institutional infrastructure of a capitalist market economy.

However, the opposite situations to the ones in which IFRs slow down the wealth creation effects of the new FRs may also happen. Adverse effects of misguided institutional arrangements introduced by new FRs, tend to be in such situation mitigated, for some time at least, by the prevailing IFRs that reduce the damage by the more slowly changing behaviour of economic agents than the 'pure' structure of incentives (in fact: disincentives) would suggest.

Again, economic history supports the contention. To give but one example, at the meeting of the European Economic Association in Lisbon in 1990 Ljubo Sirc stressed that the shift from decreasing growth to stagnation and decline should have been timed at mid-1970s also due to the departure from the labour force of the last generation that had learned how to work before the imposition of the communist economic system. That generation's stubborn efforts to stick to the earlier learned work ethics, slowed down the economic decline. But that factor ceased to exert any further positive effects with the disappearance of the last age cohort in question from the labour market (Winiecki, 1996).

The foregoing considerations may be roughly systematized in a cross-tabular form (Figure 1).

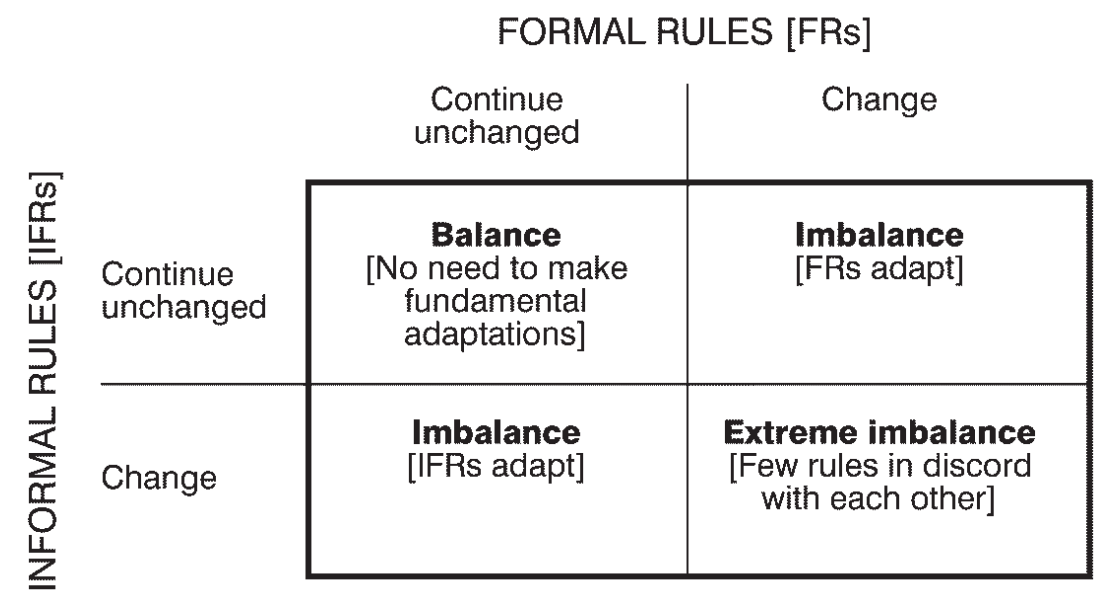

Figure 1. Cross-tabulation of possible relationships between Frs and IFRs

We see the stable situation in quadrant 1 and the extreme imbalance in quadrant 4. In the first instance no adjustment is attempted because there is no force either 
willing or able to change the existing FRs. In the second instance, close to Hobbesian anarchy, there is extreme fluidity. Rules, if any, change rapidly with the situation, making discouraging setting for the emergence of a structure incentives encouraging any wealth creation above subsistence level. The case of imbalance between FRs and IFRs are located in quadrants 2 and 3. In both instances there is a potential for adjustment: in quadrant 2 FRs adjust to the existing IFRs and in quadrant 3 the roles of FRs and IFRs are reversed. It is IFRs that adjust.

The cross-tabulation, just as any other simple systematization, does not tell us everything. There are two types of information that are missing. The first is the causes of adjustment. When IFRs adjust, it may be because the structure of incentives in new FRs is so rewarding that it overwhelms the resistance of IFRs, even if the latter have been in conflict with the former. Or it may be that the new structure of incentives is only moderately more rewarding than the old one, but the IFRs have already been roughly in concordance with the new FRs. When, in turn, FRs adjust it may, again, be due to the fact that either the resistance of IFRs is very strong in spite of relatively strong influence of FRs or the structure of incentives introduced by new FRs influences the behaviour of economic agents relatively weakly and, consequently, existing IFRs prevail (de facto or de jure).

The second missing type of important information is what goes beyond the binary choice of the adjust/non adjust type. In reality, we usually find shifts along adjust/non adjust continuum rather than either/or cases. Some friction between new FRs and existing IFRs may continue to exist or some secondary rules are introduced reducing the extent of discordance of new FRs and existing IFRs, but the thrust of new FRs have been maintained. Nonetheless, in most cases we should be able to classify the particular case as either belonging to quadrant 2 or to quadrant 3.

For analytical purposes, while looking at the cases of friction, or FRs-IFRs imbalance, the present writer suggests that we should first of all look for cases of radical changes in FRs, substantially modifying or changing the economic system,including its structure of property rights (on this point, see similar approach by North, 1990). Given that they strongly disturb prevailing informal rules, one would expect more material for studying the interaction.

Therefore, much attention should be given to the study of Eastern and East-Central Europe, which within the time-span of half a century, or in the case of the former Soviet Union within three-quarters of a century, underwent two major, discontinuous systemic changes. Modern history offers no better field to test the interaction of the radically different formal rules and the prevailing (albeit changing) informal rules.

Studying radical, discontinuous changes in FRs should help us in avoiding one more pitfall if we would like to link our research agenda to policy recommenda- 
tions. It is reasonably obvious that the probability of success is positively correlated with the degree of discordance between FRs and IFRs. The smaller the divergence, the greater the probability of success. But it is not the one and only factor of policy success. Other factors are important, too.

Thus, major changes in FRs may also succeed, even if they are relatively strongly clashing with the existing IFRs, if the new structure of incentives is strongly - and positively - influencing choices made by economic agents. Thus, it is important what kind of institutions, with what characteristics, new incentives introduce, that is to which extent they facilitate the improved performance and resultant greater scope for wealth creation (economic development). Thus, the next step should be to look at the desirable institutional characteristics enabling such developments to take place.

\section{INSTITUTIONAL CHARACTERISTICS AND OUTCOMES OF FRs-IFRs NTERACTIONS}

Individualized institutional circumstances may go a long way toward linking FRs-IFRs interaction with similar or different wealth creation outcomes. These circumstances are not unique, though. Therefore, although each historical case is unique, there is a range of 'generalizable' institutional characteristics that intervene, each in its own way, but at the same time in a more or less predictable fashion, in the relationship in question. These characteristics create a more or less hospitable (or even strongly inhospitable) environment, in which formal rules are passed and implemented, while informal rules affect - for better or worse - economic outcomes of new FRs.

Now, defining institutional characteristics as environmental ones suggests exogeneity. This is the case even if most of them characterize the nature of the state, and the state can hardly be called an exogenous factor in neo-institutional economic analysis. Nonetheless their exogeneity stems from the fact that they are yardsticks used for the purpose of locating analyzed cases on a continuum along a given dimension.

The selection process should have a starting point and for most strands of the neo-institutional economics, the starting point begins with the characteristics of the state, or more precisely the system of government. For it is the system of government that sheds light on the incentive structure under which decision makers operate, as well as on constraints on their opportunity to pursue their own interests and, therefore, on the perception of opportunity sets and trade-offs they face in the decision making process (Pejovich, 1990 and 1998). 
The state, or the system of government, can be evaluated along many dimensions. The perusal of the theoretical and historical/empirical literature for institutional characteristics most relevant for the purpose of this study resulted in the selection - undoubtedly subjective - of the following potentially useful ones:

1. Centralization/decentralization of power. We know from a number of studies, not only of neo-institutionalist persuasion, that the decentralization of power was historically conducive to the emergence of incentive structures encouraging economic agents to strive for the betterment of their conditions, that in turn gave rise to robust economies (see e.g. Lopez, 1979; North, 1981; Rosenberg and Birdzell, 1986; Mokyr, 1990). The importance of political decentralization for economic decision making stems from a greater room for maneuver available to economic agents in a politically decentralized environment.

Political decentralization might have had many facets. It could be a territorial decentralization, giving the right to make rules to lower level political units. Or it could be a functional decentralization, the most important being the one separating the right to make rules concerning lay functions of the state from the right to make rules concerning religious behaviour of individuals. In either case the political decentralization resulted in greater room for maneuver for economic agents who benefited from these opportunities. A contrast between Islamic South and Christian West is particularly striking in this respect. The very idea of the separation is blasphemous in the Islamic doctrine, while the principle of rendering unto Caesar what is Caesar's and unto God what is God's have become an established principle of Christianity since the 4th century A.D. May be less striking, but also significant is the difference in this respect between Western and Eastern Christendom. In the latter, there has been no tradition of religious authorities criticizing the lay ones (Winiecki, 1997 and 1998).

In turn, the territorial decentralization offered local economic rules that were usually more suitable for the economic and social conditions of life in a given local environment. It also insulated the local economic activities, conducted in accordance with such suitably adapted rules, from the arbitrariness or at the very least capriciousness of the central power.

Lavoie's (1985) insightful conclusion about the level of decision making points in the same direction. Analyzing successive historical 'stages' of economic organization, he pointed out that throughout economic history, not only political but also economic decision making was (usually) highly centralized. Whether it was a council of the elders of the hunters/gatherers tribe, or a king-God, or -in his view - a feudal lord of the manor, the decision has rested at the very top. An associated risk of failure in case of an economic experiment was accordingly very great as an unsuccessful departure from tradition threatened the obliteration of the tribe from the face of the earth - and only slightly less serious consequences of 
famine, contraction, and the following subjugation by other political/economic units.

It is only commercial or, later, capitalist market economy that decentralized the decision making. From then on the costs of experimenting have been dramatically reduced for it is only experimenters (and their relatives) who suffered in case of failure (incidentally, from that vantage point Lavoie supports Hayek's contention that socialism is a reactionary economic system as it recentralized the decision making - with known, disastrous consequences).

Given the foregoing, the present writer hypothesizes that the greater the level of decentralization, the greater the probability that the FRs aimed at the improved incentive structure to create wealth will encounter less friction in interaction with IFRs. With a greater extent of economic and other issues decided at lower levels, ability of individuals, or groups, to overcome custom- or other tradition-based obstacles to better their lot - by taking an advantage of an improved structure of incentives - would be undoubtedly enhanced. Therefore, the measurement problem already mentioned notwithstanding, centralization/decentralization institutional characteristic is seen as highly useful for the issue in question.

2. Strongly related to the first, and in some respects hardly distinguishable from it, is the second variable: discretion/interaction in FR-making. Here, from the classics such as de Tocqueville and Hayek (1960) to contemporaries such as North (1981 and 1990) and Powelson (1994), the role of freedom, including that to voluntarily organize and bargain with the powers that be. They say it is very important - if not decisive - for the successful long run economic performance.

The outcome of bargaining have been rules more conducive to the creation of wealth than to redistribution (associated inevitably with rent-seeking). This happened much more often under the decentralized regime than when such rules were imposed 'from above' by a centralized autocratic regime. In fact, bargaining gave sometimes birth to the emergence of a more or less constrained, but nonetheless sphere of autonomy for economic decision making, including the right to autonomously set internal rules of conduct among members of various occupations and other groups.

Wherever potentially affected parties were able to interact with the decision makers and wielded at least some (not necessarily fully countervailing!) power to wring concessions and therefore bargaining brought about a mutually acceptable solution (with the stress on mutually), the probability that such an FR will last and realize its wealth creating potential has been greatly strengthened.

The already quoted Imperial China is an illustrious example of how wealth creation enhancing measures introduced by fiat of an emperor failed to generate desired lasting economic effects. Although the reasons have been manifold, e.g. the heavy hand of imperial bureaucracy, the common understanding of the fact that 
what was arbitrarily given could be - as arbitrarily! - withdrawn, certainly contributed to the continued high level of uncertainty and consequently to high transaction costs. The foregoing deterred entrepreneurial economic agents from taking advantage of emerging opportunities.

The realization of that potential is expected to be greater as IFRs accommodate more easily to FRs when active participation in the process of rule-making in and of itself reshapes the old and shapes new conventions in a given social setting. Consequently, I would hypothesize that the more interaction has been taking place between the ruler and the affected parties, the greater the potential for successful restructuring of incentives in the direction of wealth creation rather than redistribution (rent-seeking).

However, given the powerful case that Olson (1965) built against organized interest groups as instruments of improved economic performance it seems necessary to restate the case in terms of Olsonian analysis. At the stages of political development preceding, or different from, the representative government, or at least the state where a sizeable group of citizens had guaranteed rights to participate in the affairs of the state, interest groups bargaining for a change in the structure of property rights, and within it the structure of incentives, had historically furthered the economic efficiency as the then prevailing structures of property rights in the predatory states were usually oriented toward the redistributive interests of the rulers rather than efficiency interests of wealth creators. Thus, all these merchant associations, guilds, medieval fairs, etc., more often than not, established or increased a sphere of autonomy from political decision making and, consequently, improved economic decision making that was freed from the shackles of political constraints.

It is usually at the stage of representative government that Olsonian collective action seems to tilt the balance from largely positive to largely negative economic effects. With the autonomy of economic sphere, and the right of economic agents to make their decisions autonomously already assured, interest groups could gain less from expanding the frontiers of the free market (that have already been rather widespread!) but more from bending the free market rules here and there, to benefit from monopolies, tariff protection, subsidies, etc. Therefore, for most of human history the degree of interaction between the rulers and the interest groups of the ruled brought about improvement rather than worsening of economic performance.

One more issue requires explanation before this author moves to other suggested characteristics. It is the relationship between centralization/decentralization characteristic and that of discretion/interaction as they may at times look indistinguishable. The difference is there, however difficult to discern from case to case. There is - in my view - a significant difference between, e.g., unilaterally 
granted economic autonomy to some localities (city councils) or associations (merchant groups or guilds) and negotiated solutions that explicitly limit the rights of the ruler in some respects (such as, e.g., those embodied in the Revolution Settlement of 1689 in England). The former may be more easily revoked than the latter (a point argued by Powelson, 1994), enhancing credibility of negotiated arrangements resulting from intensive interaction.

Two different stories from communist Chinese history offer a more elaborated explanation of the outlined difference. In the second part of the 1950s Mao Zedong launched a Hundred Flowers liberalization campaign ('Let the hundred flowers bloom, let the hundred schools of thought compete'). However, as the extent of criticism of the communist regime became known, the campaign was ended as unilaterally as it began, with dissidents imprisoned, disgraced, and persecuted thereafter. This unilateral action stifled dissent for the next two decades or more, with disastrous results in the economic sphere as well (with hardly anybody daring to criticize distortive or downright lunatic policies of the communist leadership).

Another liberalization launched by Deng Xiaoping in the late 1970s has been very different in nature. Learning from past mistakes, Deng and his followers deliberately limited their decision making powers through territorial decentralization. Some local governments, especially in Southeast China, thus obtained a considerable discretion over economic decision making within their territories. As local authorities adjusted centrally issued FRs to suit local conditions, often with grudging or only tacit acceptance from dissatisfied elements in the central government (and central organs of the Communist Party), they gained credibility and substantial entrepreneurial activity and economic development followed. Interaction and bargaining led to increased credibility as the entrenched powers of local authorities could not be easily revoked.

3. Degree of regulation vs. degree of economic freedom. The system of government affects opportunities to benefit from potentially wealth creation enhancing FRs in many ways. The degree of economic freedom (understood here as the degree of freedom of economic agents to eliminate existing errors and to pursue new trials to improve performance) underpins competitiveness of markets. However, at various times, in various places, those pursuing economic activities have been more or less constrained by rulers' issued regulations (FRs) as to what, when, where, and even how and from what they should produce, quite apart from otherno less onerous - constraints imposed by other types of regulations.

And yet we have known for a long time (see, Hayek, 1960) that the more economic freedom both formal and informal rules allow, the better. But since in the overregulated environment freedom to begin new trials and eliminate revealed errors, is more or less severely constrained (see in different ways Olson, 1982; 
Pelikan, 1985 and 1986), a high degree of regulation, or overregulation, may be identified with one end of the continuum at the other end of which is a liberal 'night watchman' state, offering maximum economic freedom.

It is in the latter environment that one would expect less friction between the FRs, conducive to reduction in transaction costs and neoclassical production costs, and therefore to increases in wealth creating capability, and IFRs. In such an environment customs and other social conventions would not be expected to congeal as ongoing multitudinous trials and errors would instill enough adaptability (or long term flexibility, see Neuber, 1995) into the economy.

The foregoing is not intended to suggest that the environment without any rules would be most conducive to economic development. A decentralized, free enterprise economy still needs Hayekian 'general rules'. But there exists a kind of Laffer curve of the degree of regulation. After passing the threshold of the modest but mutually consistent set of rules, the growing extent and intensity of regulation affects increasingly adversely the capability of the economy to add to the existing wealth. This is shown in Figure 2.

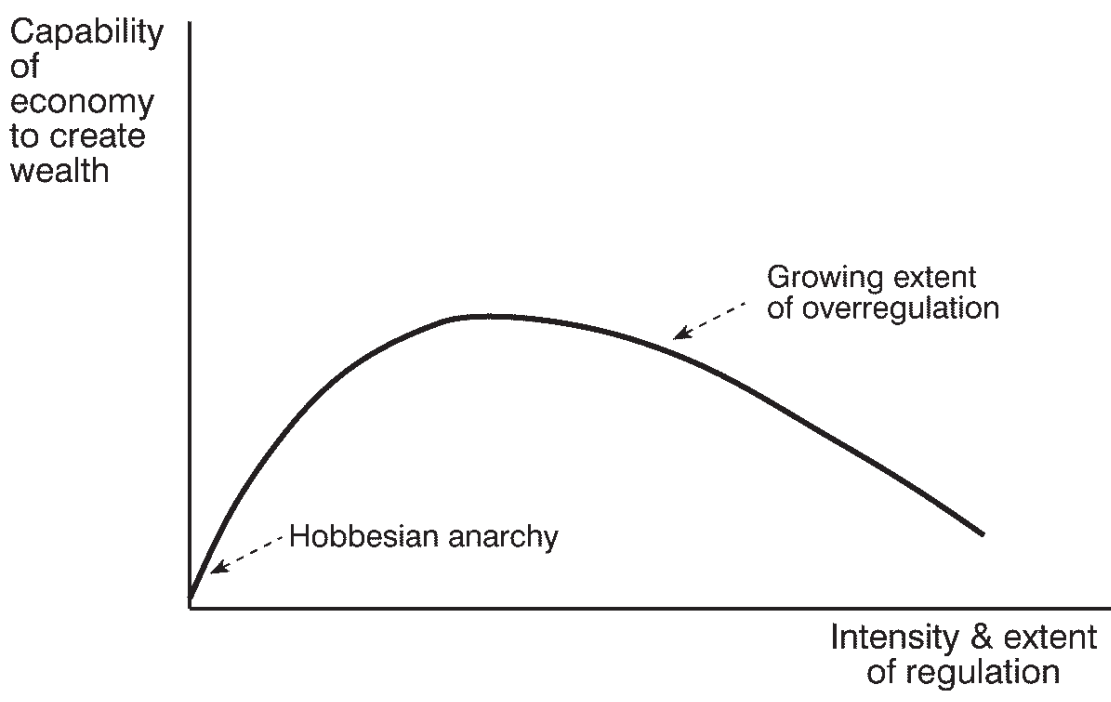

Figure 2. Institutional 'Laffer Curve'

4. Of those institutional variables associated primarily with the state, yet another has been formulated for the purpose of this study, namely the existence/nonexistence of competitive pressures upon rulers to follow arrangements successful elsewhere. Its importance stems from the European experience in the period between circa 950 and 1850 so eloquently argued in Rosenberg and Birdzell (1986). 
Technical, organizational and social innovations were on the whole imitated fairly soon, given the limited geographic distance between alternative centres of political power and lively communication flows. And if they were not, where Hirschmanian 'voice' of the interested groups did not help, 'exit' did, as the departure of merchants, artisans/manufacturers, or financiers deprived resistant rulers of the sources of tax income (and not easily replaceable human capital). The decline of 17th century leading Italian city states and the late 20th century American 'rustbelt' states, associated with the migration of money and talent elsewhere, are past and present cases in point.

The historical failure of Imperial China to generate lasting economic development my also partly be ascribed to the now considered lack of institutional competition. The Imperial China faced throughout its history two types of challenges. One was coming from nomadic peoples invading China from the North. But it was a military challenge of peoples who offered little that was worth imitating in economic terms. Another, also repeatedly faced challenge, was that of political fragmentation and intermittent wars of conquest pursued by various Chinese warlords. But the latter challenge again offered little, if anything, to imitate since warlords modeled their fiefdoms along the imperial lines, with its centralization, discretionary decision making, and regulation 'from above' of most aspects of economic activities. Not much competing diversity emerged - and was imitated as a result.

It is worth noting that the only partly successful case of imitation in China has been taking place now, that is after the emergence of highly successful alternatives in the vicinity of communist China (Japan and later the 'Little Dragons') that threatened to have made communist China an ever poorer relation of the Sinic area. Sun Yat-Sen's revolution of the early 20th century also did not succeed because only very distant models in Western Europe and the United States were the basis of an attempted institutional change.

Institutional competition should not be regarded, however, as time and place specific. The size of political units in various parts of the world at various times has not been necessarily larger. And when and where it does at present, the increase in size is compensated by the shrinkage of the world in communication terms. In the era of global communication, the information on innovations that were successful elsewhere is within reach of every ruler or ruling group. What is needed for competitive pressures of that sort to arise, is some regional political set-up, where emulation of the more successful presses resistant rulers to accept solutions increasing economic pie. This may be even in the face of the non-growing (or non-commensurately-growing) ruler's 'take'.

In this author's opinion East Asia, joined in about a decade later by South-East Asia, created a somewhat similar environment, where the emulation of each 
other's successes resulted in a progressively freer economic landscape throughout the region. From there stem frantic efforts of Chinese communist and Iranian theocratic rulers to cut their population off from international interchange of ideas (while expanding trade ties). But in the age of faxes, mobile phones, e-mail, internet and other systems, they are doomed to fail sooner or later.

Interstate political competition, where economic agents vote with their feet (and money), is undoubtedly more difficult in the contemporary world, that is controlling migrations much more thoroughly than at any time in the past. Except, of course, the communist states of the past - and North Korea's tragic present. So, all the more stress is put on the flow of the relevant information that cannot be impeded for technological reasons anymore. But the usefulness of this variable is beyond doubt (even if its elusiveness, unfortunately, is not). The flow of usable economic information via itinerant traders, traders' correspondence, regional fairs' of the distant past, via long term merchant voyages, establishment of trading posts, etc., of the early modern era, or via press, telecommunication and computer networks of the present - all affected and increasingly affect today the shape of social conventions and beliefs. And not only their shape but also the adaptability of societies per se.

5. The level of corruption is a characteristic that may raise objections concerning the internal coherence of recommended variables. For it may be said that corruption already is informal rules' response to the perceived unfairness and/or inefficiency of formal rules. This charge is undoubtedly true, but at the same time corruption, if substantial, is a source of friction per se. Once it takes deeper roots, new FRs tend to get weakened or distorted as transaction costs tend to increase or decrease by much less than expected from the original restructuring of the property rights enhancing the creation of wealth. Thus, the more corruption is already rooted in a given economy, the greater - one hypothesizes - will be the friction between FRs and IFRs and, therefore, the greater the differential between potential and actual effects of the wealth creation enhancing FRs.

6. The last selected variable is belief system or Weltanschaunng of a society placed somewhere along the individualist/collectivist continuum. By including this rather elusive variable, the present writer is accepting the dictum of Sowell (1996) that there are systematic differences between ethnic and other groups, large and small, in their ability and willingness to better their living conditions, and that these differences stem largely from divergent philosophies, worldviews, religious or ideological beliefs, etc. It also follows North (1990) who stressed that religious beliefs or ideologies people hold may be of the kind that give preferences to solutions characterized by low adaptive efficiency, piling up one error upon another. 
Thus, however elusive the evaluation may be, an effort should be undertaken to evaluate what the actual belief system is and how it fits, however approximately, into the continuum along the collectivist/individualist lines, and even more importantly, and somewhat less approximately, how it compares with a reference country or a group of countries. Recent papers by Brenner (1990), Greif (1994) and Winiecki (1997) tend to reinforce the importance of that institutional variable. Thus, the selection yielded a number of institutional characteristics able - in the opinion of the present writer - to affect the relationship between the FRs-IFRs interaction and economic outcomes. Their systematic application to a large number of cases from different civilizations and different historical periods should be expected to generate useful regularities (on the format, see Figure 3).

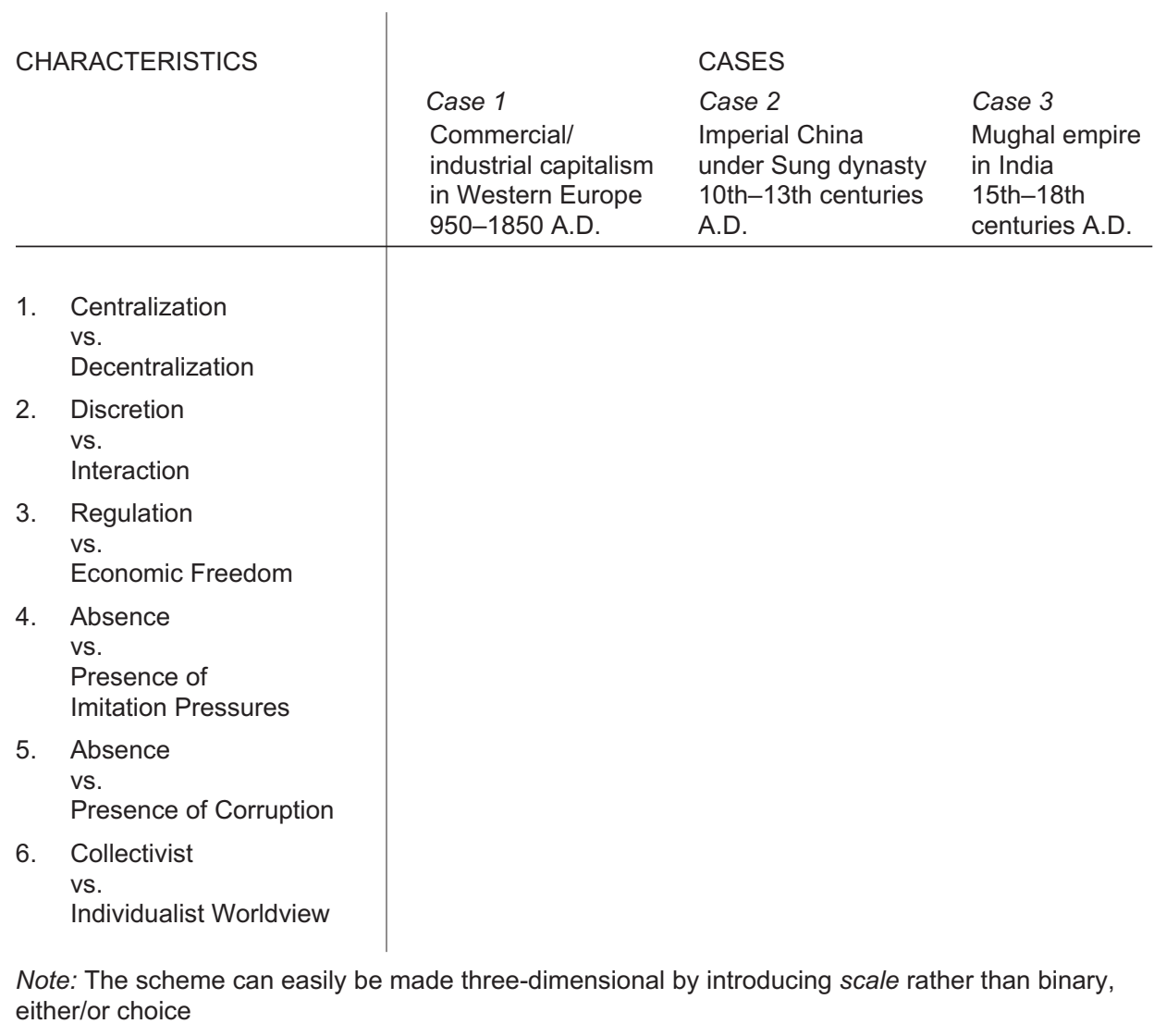

Figure 3. Institutional characteristics and historical cases of FRs-IFRs interaction 
Of course, given the qualitative nature of our characteristics, tests are of different, non-econometric nature, as stressed already in the preliminary section of this essay. However, since we offer a range of characteristics that can be applied to each analyzed case of FRs-IFRs interaction, their qualitative nature should not adversely affect the rigor of evaluation, as at least some of the characteristics are expected to be applicable in each particular case.

Now, having listed the institutional characteristics most relevant for the analysis in question, some explanations are in order to defuse potential criticism. It has been stressed in a debate on an earlier version of this essay, that most characteristics listed above as relevant to the study of FRs-IFRs interaction in the context of economic outcomes of such interaction, point to the superiority of a decentralized market economy of some sort (I am in debt to Eggertsson (1990) on highlighting this point). However, the foregoing coincidence should not be regarded as a bias of sort. On the contrary, if the range of institutional characteristics points to an existing institutional pattern, then the pattern in question should be expected to appear, on the average, more often, wherever economic success is the outcome. This has been the case so far within the Western Christendom, as shown by Rosenberg and Birdzell (1986), as well as earlier in different periods of imperial China, pre-Meiji Japan or more contemporarily among East Asian 'Dragons' (their present problems notwithstanding).

The next step of the research agenda is to approach a change in outcomes of a given FRs-IFRs interaction over time. It is to the subject of change in question that this writer now turns his attention.

\section{CHANGING ECONOMIC OUTCOMES OF FRs-IFRs INTERACTION OVER TIME}

It has been suggested in the preliminaries of this essay that economic outcomes resulting from the FRs-IFRs interactions - helped to explain and predict by the already listed characteristics - are changing over time. Some of these changes are stemming directly from the very novelty of the FRs and the more the new FRs differ from old ones, the greater are transaction costs associated with learning. To give but one example, learning the market rules in post-communist economies of East-Central and Eastern Europe after some 50-75 years of radically different economic system must have entailed very substantial transaction costs (see e.g. Schmieding, 1993; Winiecki, 1993 and 1995).

But it is usually maintained that economic outcomes change also in subtler and more lasting ways as culture, encompassing a major part of what is called 'informal rules' here, changes slowly under the impact of economic forces. Marshall 
noted the foregoing already a century ago, when he wrote that "sometimes these forces break down the custom altogether; but often they evade it by gradual and imperceptible changes ... [and later:] ... Customs ... have ever been imperceptibly growing and dwindling again, to meet the changing exigencies of successive generations" (quoted in Jones, 1988, p. 99).

Thus, culture, or informal rules, should not be regarded as unyielding obstacles (Jones, ibid.). Sociologists and anthropologists have, however, more reservations about the ability of changes in economic incentives to erode informal rules (see, e.g., Platteau, 1994). Therefore, it may be said, without prejudicing the judgement, that friction resulting from FRs-IFRs interaction may either reduce - and decreasingly so - potential benefits from wealth creation enhancing changes in the structure of incentives, or it may frustrate the efforts to realize the potential altogether. All interested in the subject seem to agree on one point, namely that the adaptation processes (or non-adaptation processes as some would have it) are of long-lasting nature.

Under certain circumstances, highlighted by the characteristics presented in the preceding section, this is what has more often than not been the case. And the foregoing applies not only to cases of wealth creation enhancing but also wealth creation damaging FRs. Views of the unyielding nature of IFRs apart, the foregoing may be formalized in a number of ways.

North (1990), using traditional economic apparatus, maintains that there is a trade-off between wealth and the value hierarchy based on IFRs, or what he calls 'ideologies, altruism, and self-imposed standards of conduct' [ibid., p. 22). In his view this trade-off is a negatively sloped function of wealth in terms of the latter: the higher the price, in terms of wealth forgone, of sticking to one's values, the less one's value preferences would weigh in the individual's decisions. Diagrammatically speaking, much depends on the steepness of the slope, as shown in Figure $4 a$.

A question should be asked, however, whether the foregoing is a good description of reality as we know it from history. After all, history, including economic history, has been punctuated by sudden accelerations and decelerations, as well as sudden discontinuities. To allow for this in our evaluation of the role of time in changing economic outcomes of FRs-IFRs interaction, a concept of threshold should be introduced. How it fits into our considerations of FRs-IFRs interaction is best presented in terms of Lindbeck (1995) views on the hazardous impact of the welfare state.

He underlines the role of social norms, that is our IFRs, in constraining economic behaviour by interposing themselves between formal rules and economic outcomes. In the case of Western welfare state it means that its negative effects on work habits, etc., are delayed. These constraints may affect behaviour for quite 
long - he insists - but not forever. Once a substantial number of individuals notice that others do not behave in accordance with social norms historically prevalent in a given society, defections multiply, that is incentives-based, here: welfare disincentives-based behaviour begins to dominate, with severe adverse consequences. Sometimes, he adds, an exogenous event may play a catalytic role in pushing the economy toward the hazardous future.
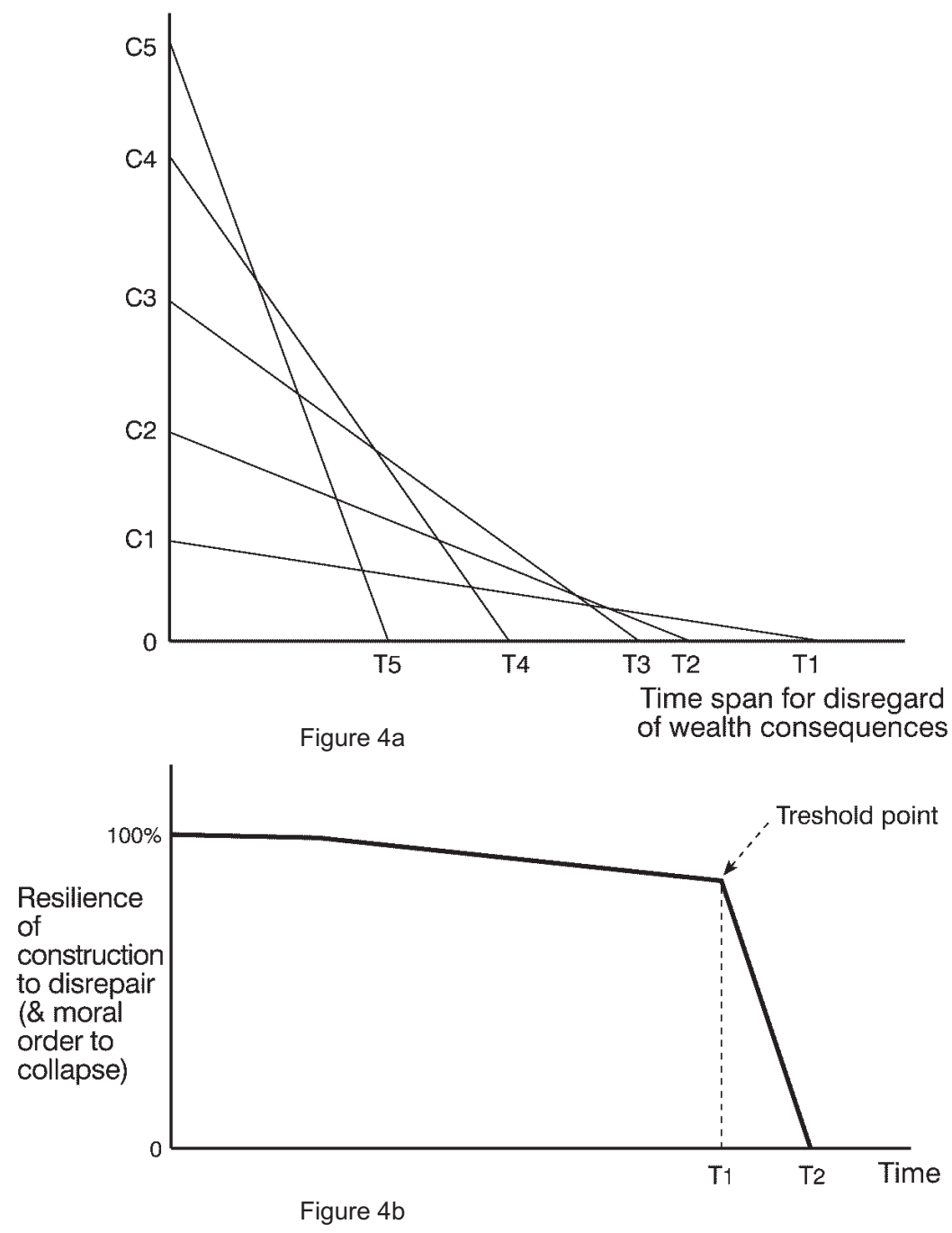

Figure 4. Alternative concepts of resilience of informal rules 
Diagrammatically speaking, there is then a threshold of sort, passing which the economy, so to say, falls over the brink. The threshold role may be, following Lindbeck, an exogenous event. The foregoing is close to architects' perception of consequences of the disrepair. They talk about the 'sudden death' of a building, or sudden collapse when the length of the disrepair period and resultant damages exceed the resilience capability of a given physical structure. The whole construction, almost intact until then, collapses in a very short time. This is presented in Figure $4 b$, where the threshold is located at point A.

A threshold approach to economic outcomes of FRs-IFRs interaction seems to better reflect both cases of economic fall of empires, countries, and territories, as well as sudden accelerations of economic development long after institutional conditions and actual policies have created potential for such acceleration.

There is, however, a hidden puzzle involved here. Whether in North's or in Lindbeck's term, informal rules are expected to work in a long, if not a very long term. As Loury (1987), quoted by Lindbeck (ibid.), says, social (collective) capital accumulates and decumulates over decades and centuries. But we do know from history that human behaviour changed relatively, or even absolutely, very quickly. Let us consider, then, an exemplary case.

It is a well known fact for Sovietologists, as well as for all those in the West who ever made business deals with communist organizations, that both goods and services in the communist system, save special circumstances, were of very low quality. But it is much less well known how quickly the - variously measured quality deteriorated. Hungarian historian Berend (1990), going through industrial bureaucracy's archives, found that the defect rate in case of light industry goods multiplied dramatically, by a factor of ten or even twenty, in just 2-3 years since the imposition of the central planning! The same applied to other measures such as variety that shrunk often by as much as a factor of ten. Other indicators and industries tell a similar story. Taking the example at face value one would have to concede that the work ethics, an important component of culture, and more widely IFRs, was corroded under communism in an unbelievably short time. But on the other hand we have a very plausible assertion of Sirc (see the preceding section) that certain work ethics qualities of the generations that began their working life before communism slowed down the decline of the system that began to be increasingly visible only when they went into retirement. The solution of the puzzle may lie in the position taken from social psychology by Shiller, Boycko, and Korobov (1992). They seem to distinguish factors that are attitudinal from those that are situational. The former are reflections of deeper traits related to psychological characteristics, personality and culture. The latter, however, are related to individuals' perceptions of the reality as it constrains their behaviour. 
Although both belong largely to the category of informal rules, one would argue that the speed of change, with which economic agents, and individuals in general, disregard these rules, given the structure of incentives, must be markedly different. Thus, superficially it may be argued that there is some room for accommodation of both evidence presented by Berend (and many others who studied the problem), once we submit that those who reduced quality of their work simply reacted to situational factors, and the Sirc thesis about the influence of the pre-communist generation on the work environment under communism.

The former pertains to short term reactions to dramatically changed reality, while the latter associates with more complex choices made during one's working life under communist rule. This is, in the opinion of the present writer, a somewhat superficial answer, as there is no denying that work ethics is a part of internalized morals and, an apparent, very rapid adjustment of work habits to a new structure of incentives must be thoroughly disquieting...

A complementary, and partial, answer to the puzzle in question is offered by the present writer. Although in my opinion the ability to reduce the quality of work under communism cannot be explained within the framework of the ingrained work ethics rationale, the rapid improvement in quality (as well as productivity) during the transition to the market may be explained more easily. It is noticed by production experts that the progress in both quality and quantity in post-communist countries in transition is different across economic sectors. It has been the most impressive in manufacturing, and least impressive in construction and some services. Thus, it may be posited that improvements have been most noticeable, wherever the private property rights structure strengthened the control of owners and/or managers over production processes. Thus, individuals adjusted their work habits rapidly because they had to if they wanted to capture the benefits of a new structure of incentives. They would be as ready to shirk, cheat, or steal, as they were before the start of transition. But clearly they have been unable to do so without paying the price (lower earnings or dismissal). Wherever due to the nature of a product, like in construction, the quality of a given structure is revealed only gradually (once the building is inhabited or used for office or production purpose), the quality improvements have been the smallest (and by the same token the opportunity to shirk, cheat, or steal the largest).

Thus, we may hypothesize that the much debated decline in work ethics under communism is a fact and that to change that attitude a lot of time has to pass, but in situations of strong external controls - such as on the production line - workers, willy-nilly (by and large 'nilly' rather than 'willy') but nonetheless rapidly improve their performance in response to new incentives. These improvements are less impressive, where such controls are weaker, in spite of the fact that the structure of incentives changed in all sectors of the economy in the same manner. 


\section{REASSUMPTIONS}

In the essay, the present author tried to consider a simple question but an important one for economic development, namely what happens when formal rules and informal rules are in discord with each other. The basic idea behind asking such a question has been that even the best wealth creation- enhancing 'rules of the game' introduced in different political, economic, and socio-cultural environments must of necessity bring about different outcomes. The history of both the Western and non-Western world is replete with examples confirming the foregoing perception.

In explaining and predicting the economic outcomes of new formal rules as mediated by the interaction with informal ones, certain characteristic features of economic regimes are often present, indicating the probability of better or worse performance (higher or lower transaction costs and neoclassical production costs) under given circumstances. Therefore, the list of such characteristics, relevant for the analysis in question, has also been recommended in the essay.

Finally, it has been stressed that economic outcomes of FRs-IFRs interaction are not invariant; they tend to change over time. These changes result from the growing impact of new formal rules upon the then prevailing informal ones. I posited that it is also FRs that may adapt to IFRs, upon encountering strong resistance - again with consequences for economic outcomes. One way or another, economic outcomes of the analyzed interaction change over time but what also matters is a manner in which these changes occur (gradual change or sudden collapse).

\section{REFERENCES}

Berend, T. I. (1990): The Hungarian Economic Reform, 1953-1988. Cambridge University Press. Brenner, R. (1990): The long road from serfdom and how to shorten it. The Canadian Business Journal, Vol. 17, number 2, December.

Cooter, R. D. (1996): The rule of state law and the rule-of-law state: Economic analysis of the legal foundations of development, in: Annual World Bank Conference on Development Economics. Ed. by M. Bruno and B. Pleskovic.

Eggertsson, T. (1990): Economic Behavior and Institutions. Cambridge University Press.

Furubotn, E. and Richter, R. (1991): The new institutional economics: An assessment, in: The New Institutional Economics, College Station, Tx.: A\&M Press.

Greif, A. (1994): Cultural beliefs and the organization of society: A historical and theoretical reflection on collectivist and individualist societies. Journal of Political Economy, Vol. 102, No. 5.

Hayek, F. A. (1960): The Constitution of Liberty. Chicago, University of Chicago Press.

Jones, E. L. (1998): Growth Recurring. Economic Change in World History. Oxford, Clarendon Press.

Acta Oeconomica $51(2000 / 2001)$ 
Lavoie, D. (1985): National Economic Planning. What Is Left? Cambridge, Mass.: Ballinger.

Lindbeck, A. (1995): Welfare state disincentives with endogenous habits and norms. Scandinavian Journal of Economics.

Lopez, R. S. (1979): The Commercial Revolution of the Middle Ages, 950-1350. Cambridge University Press.

Loury, G. (1987): Why should we care about group inequality? Social Philosophy and Politics, Vol. 5, pp. 249-271.

Miskimin, H. A. (1969 ): The Economy of Early Renessaince Europe, 1300-1460. Englewood Cliffs, N. J.: Prentice-Hall, Inc.

Mokyr, J. (1990): The Lever of Riches: Technological Creativity and Economic Progress. New York: Oxford University Press.

Neuber, A. (1995): Adapting the economies of Eastern Europe: Behavioural and institutional aspects of flexibility, in: The Flexible Economy. Ed. by T. Killick. London: Routledge.

North, D. C. (1979): A framework for analyzing the state in economic history. Explorations in Economic History, July.

North, D. C. (1981): Structure and Change in Economic History. New York: Norton.

North, D. C. (1990): Institutions, Institutional Change and Economic Performance. Cambridge University Press.

Olson, M. (1965): The Logic of Collective Action. Cambridge, Mass.: Cambridge University Press.

Olson, M. (1982): The Rise and Decline of Nations. New Haven: Yale University Press.

Pejovich, S. (1990): The Economics of Property Rights. Towards a Theory of Comparative Economic Systems. Dordrecht: Kluver.

Pejovich, S. (1998): Economic Analysis of Institutions and Systems. Revised 2nd edition, Dordrecht: Kluver.

Pelikan, P. (1985): Private Enterprise v. Government Control: An Organizationally Dynamic Comparison. Working paper 137. Stockholm: Industrial Institute for Economic and Social Research.

Pelikan, P. (1986): Institutions, Self-Organization, and Adaptive Efficiency: A Dynamic Assessment of Private Enterprise. Working paper 158. Stockholm: Industrial Institute for Economic and Social Research.

Platteau, J-P. (1994): Behind the market stage where real societies exist - Part I: The role of public and private order institutions. Journal of Development Studies, Vol. 30, No. 3.

Powelson, J. P. (1994): Centuries of Economic Endeavor. Ann Arbor: Michigan University Press.

Rosenberg, N. and Birdzell, L. E. Jr. (1986): How The West Grew Rich. New York: Basic Books.

Schmieding, H. (1993): From plan to market: On the nature of transformation crisis. Weltwirtschaftiches Archiv, Vol. 129, No. 2.

Shiller, R. J., Boycko, M. and Korobov, V. (1992): Hunting for Homo Sovieticus: Situational versus attitudinal factors in economic behavior. Brookings Papers on Economic Activity, No. 1.

Sowell, T. (1996): Race and Culture. A World View. New York: Basic Books.

Voigt, S. (1993): Values, norms, institutions and the prospects for economic growth in Central and Eastern Europe. Journal des Economistes et des Etudes Humaines, Vol. 4, No. 4.

Winiecki, J. (1993): Formal and Informal Constraints in Transition to the Market. A paper prepared for the Libert Fund symposium on 'Moral Foundations of a Free Society', Madralin, Warsaw, July 4-7, 1993, mimeo.

Winiecki, J. (1995): Formal and informal constraints in transition to the market: Costs of neoclassical utility maximisation. Communist Economies and Economic Transformation, Vol. 7, No. 2.

Winiecki, J. (1996): Russlands schwierige Rückkehr zur Normalität: Fehlende Normen als Hindernis für die Marktwirtschaft. Neue Zürcher Zeitung, December 3. 
Winiecki, J. (1997): Transforming to economic freedom: At high cost; often with long lags, and not without question marks. Journal of Public Policy, Vol. 17, No. 3, pp. 251-268.

Winiecki, J. (1998): Formal and informal rules in post-communist transition. Journal of Public Finance and Public Choice, Vol. 16, No. 1. 